\title{
Screen-based sedentary behaviours among a nationally repre- sentative sample of youth: are Canadian kids couch potatoes?
}

\section{S. T. Leatherdale, PhD (1); R. Ahmed, PhD (1,2)}

This article has been peer reviewed.

\section{Abstract}

Purpose: To determine the percentage of Canadian youth meeting screen-time guidelines and to identify characteristics associated with different screen-time behaviours.

Methods: Using nationally representative data collected from the 2008/2009 Youth Smoking Survey (YSS), we analyzed three screen-time behaviours, cigarette smoking, weekly spending money, self esteem, region and grade by sex, and conducted four logistic regression models to examine factors associated with more than 2 hours a day of sedentary screen time.

Results: Of 51922 Canadian youth in grades 6 to 12, 50.9\% spent more than 2 hours per day in screen-based behaviours. The average daily screen time was $7.8( \pm 2.3)$ hours. Males and current smokers were more likely to report over 2 hours per day watching TV and videos or playing video games, whereas students in higher grades and those with weekly spending money were more likely to report playing or surfing on a computer. Youth with higher self-esteem were less likely to report spending over 2 hours per day in each of the three screen-time behaviours examined.

Conclusion: Developing a better understanding of the factors associated with more hours of screen time is required to develop and target interventions that reduce screen-time behaviours.

Keywords: sedentary behaviour, youth/child, screen time, Youth Smoking Survey, tobacco, surveillance, self esteem

\section{Introduction}

Screen-based sedentary behaviours likely have a negative impact on many different aspects of youth health and development. ${ }^{1-2}$ For instance, the increasing trend in youth obesity in North America coincides with an increasing prevalence of youth reporting over 3 hours of screen time per day. ${ }^{3}$ The American Academy of Pediatrics ${ }^{4}$ has developed guidelines that recommend limiting children's total entertainment screen time to no more than 1 to 2 hours of quality programming per day. Considering that few Canadian youth currently meet these recommendations, ${ }^{5-6}$ activities designed to reduce sedentary screen time among youth should be a public health priority.

A substantial body of research has examined characteristics associated with watching television (TV). ${ }^{3,6-8}$ More recently, other types of sedentary screen-time behaviours have also garnered attention, for example, playing video games and using computers. ${ }^{5,6,8}$ It seems that youth are more likely to spend time in these types of screen-based behaviours if they are male, ${ }^{5,6,9-11}$ older, ${ }^{5,9,11}$ from a low income family ${ }^{9}$ or if they engage in risk behaviours such as smoking. ${ }^{12}$ Given that this is also a developmental period when youth's self-esteem is associated with the likelihood of their engaging in health-promoting or inhibiting behaviours, ${ }^{13}$ it is important to determine if screen time is associated with self-esteem. Considering that excessive screen time is associated with an increased risk of obesity ${ }^{1,3}$ and engaging in other risk behaviours, ${ }^{5}$ a better understanding of different screen-time behaviours would provide valuable insight for targeting or tailoring interventions to prevent or reduce screen time among youth populations.

The purpose of our study was to determine the percentage of Canadian youth who exceed the recommended screen time guideline and to identify characteristics associated with different screen-time behaviours.

\section{Methods}

Our study used nationally representative data collected from 51922 students in grades 6 to 12 as part of the 2008/2009 Canadian Youth Smoking Survey (YSS). ${ }^{14}$ In brief, the target population for this study consisted of all young Canadian residents in grades 6 to 12 attending public and private secondary schools in 10 Canadian provinces. The YSS was administered to students during class time, and participants were not compensated. To reduce demands on schools and to increase student participation rates, the YSS used active information with passive consent.

Author references

1. Department of Health Studies and Gerontology, University of Waterloo, Waterloo, Ontario, Canada 2. Department of Statistics and Actuarial Science, University of Waterloo, Waterloo, Ontario, Canada

Correspondence: Scott T. Leatherdale, Department of Health Studies and Gerontology, University of Waterloo, 200 University Avenue West, Waterloo ON N2L 3G1 Tel.: (519) 888-4567 ext 37812; Fax: (519) 886-6424; Email: sleather@uwaterloo.ca 
The YSS asked respondents to report the average number of hours per day that they spent (a) watching TV or videos, " (b) playing video games and (c) playing games or surfing the Internet on a computer. Respondents could choose from "none," "less than 1 hour a day," " 1 to 2 hours a day," "more than 2 hours a day but less than 5 hours a day," or " 5 or more hours a day" for each behaviour. Consistent with existing research $^{8,15}$ and guidelines, ${ }^{4}$ we grouped responses for each construct into two categories ( $\leq 2$ hours/day, $>2$ hours/day) for each individual activity and for the total screen time. We calculated a conservative estimate of the mean screen time per day based on the lowest value of each response category reported. The YSS also collected information on demographics, cigarette smoking behaviour, weekly spending money and self-esteem. Specific details on these measures are available elsewhere. ${ }^{\dagger}$

We examined descriptive analyses of our three sedentary behaviour constructs as well as cigarette smoking behaviour, weekly spending money, self-esteem, region and grade by sex. We then conducted four logistic regression models to examine factors associated with watching TV or videos, playing video games, and playing or surfing on a computer for more than 2 hours a day per each behaviour as well as total screen time for more than 2 hours a day. Survey weights for descriptive statistics were used to adjust for differential response rates across regions or groups; the statistical package SAS version 8.02 was used for all analyses. ${ }^{16}$

\section{Results}

\section{Respondent characteristics}

The study sample was $48.7 \%$ male and $51.3 \%$ female, representing $1388 \quad 139$ boys and 1460341 girls. Among students in grades 6 to $12,30.2 \%(\mathrm{n}=836518)$ rep-orted watching over 2 hours of TV or videos per day (mean $3.0 \pm 0.9 \mathrm{~h} / \mathrm{d}$ );

\footnotetext{
* Video time refers to TV series or movies watched at home, on video tape, DVD or Blu-ray. In our preliminary research validating the comprehension of these measures with youth populations, the youth we sampled interpreted the term "video" to refer to any type of movie or TV series watched at home.
}

$13.7 \%$ ( $\mathrm{n}=372$ 132) reported playing video games for over 2 hours per day (mean $2.1 \pm 1.1 \mathrm{~h} / \mathrm{d})$ and $29.9 \%(\mathrm{n}=814$ 116) reported playing or surfing on a computer for

over 2 hours per day (mean $2.9 \pm 1.1 \mathrm{~h} / \mathrm{d}$ ). Overall, 50.9\% ( $n=1439$ 311) of Canadian youth spent over 2 hours per day on total screen time (Table 1).

\section{TABLE 1}

\section{Descriptive statistics for youth in the Youth Smoking Survey by sex, 2008/2009, Canada}

\begin{tabular}{|c|c|c|c|c|}
\hline & & $\begin{array}{c}\text { Male } \\
(\mathrm{n}=1388 \text { 139) } \\
\%^{\mathrm{a}}\end{array}$ & $\begin{array}{c}\text { Youth } \\
\text { Female } \\
(\mathrm{n}=1460341) \\
\%^{\mathrm{a}}\end{array}$ & 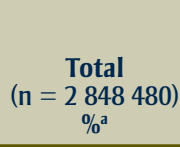 \\
\hline \multicolumn{5}{|l|}{ Grade } \\
\hline 6 & & 13.1 & 13.6 & 13.3 \\
\hline 7 & & 13.8 & 14.2 & 14.0 \\
\hline 8 & & 14.3 & 14.5 & 14.4 \\
\hline 9 & & 14.9 & 14.8 & 14.8 \\
\hline 10 & & 15.5 & 14.8 & 15.2 \\
\hline 11 & & 14.9 & 14.7 & 14.8 \\
\hline 12 & & 13.5 & 13.4 & 13.5 \\
\hline \multicolumn{5}{|l|}{ Smoking status } \\
\hline Never smoker & & 90.1 & 92.5 & 91.3 \\
\hline Current smoker & & 8.9 & 6.4 & 7.7 \\
\hline Former smoker & & 1.0 & 1.1 & 1.0 \\
\hline \multicolumn{5}{|l|}{ Weekly spending money, \$ } \\
\hline 0 & & 21.9 & 19.0 & 20.5 \\
\hline $1-20$ & & 38.4 & 41.4 & 39.8 \\
\hline 21-100 & & 24.1 & 27.1 & 25.6 \\
\hline$>100$ & & 15.6 & 12.5 & 14.1 \\
\hline \multicolumn{5}{|l|}{ Self-esteem (derived score from 0 to 12) } \\
\hline $0-4$ & & 1.8 & 3.3 & 2.6 \\
\hline $5-8$ & & 23.3 & 38.4 & 30.6 \\
\hline 9 & & 16.2 & 17.2 & 16.7 \\
\hline 10 & & 20.6 & 16.4 & 18.6 \\
\hline 11 & & 22.5 & 15.3 & 19.0 \\
\hline 12 & & 15.6 & 9.4 & 12.5 \\
\hline \multicolumn{5}{|l|}{ Region } \\
\hline Atlantic Canada ${ }^{\mathrm{b}}$ & & 6.7 & 7.2 & 6.9 \\
\hline Quebec & & 19.3 & 19.4 & 19.4 \\
\hline Ontario & & 41.4 & 40.5 & 40.9 \\
\hline Prairies $^{c}$ & & 18.8 & 19.0 & 18.9 \\
\hline British Columbia & & 13.8 & 13.9 & 13.9 \\
\hline \multicolumn{5}{|l|}{ Screen-time behaviour (average h/d) } \\
\hline \multirow[t]{2}{*}{ Watching TV or videos ${ }^{\mathrm{d}}$} & $\leq 2$ & 68.8 & 70.8 & 69.8 \\
\hline & $>2$ & 31.2 & 29.2 & 30.2 \\
\hline \multirow[t]{2}{*}{ Playing video games } & $\leq 2$ & 76.6 & 96.6 & 86.3 \\
\hline & $>2$ & 23.4 & 3.4 & 13.7 \\
\hline \multirow[t]{2}{*}{ Playing/surfing on a computer } & $\leq 2$ & 71.7 & 68.3 & 70.1 \\
\hline & $>2$ & 28.3 & 31.4 & 29.9 \\
\hline \multirow[t]{2}{*}{ Total screen time (all behaviours) } & $\leq 2$ & 46.4 & 52.0 & 49.1 \\
\hline & $>2$ & 53.6 & 48.0 & 50.9 \\
\hline
\end{tabular}

Abbreviations: $\mathrm{Cl}$, confidence interval; d, day; h, hour; $\mathrm{n}$, sample size.

a Weighted population estimate.

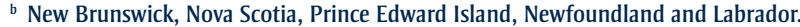

c Alberta, Saskatchewan, Manitoba.

d "Videos" refers to TV series or movies watched at home, on video tape, DVD or Blu-ray. 
FIGURE 1

Prevalence of sedentary behaviours by region, Canada, 2008/2009

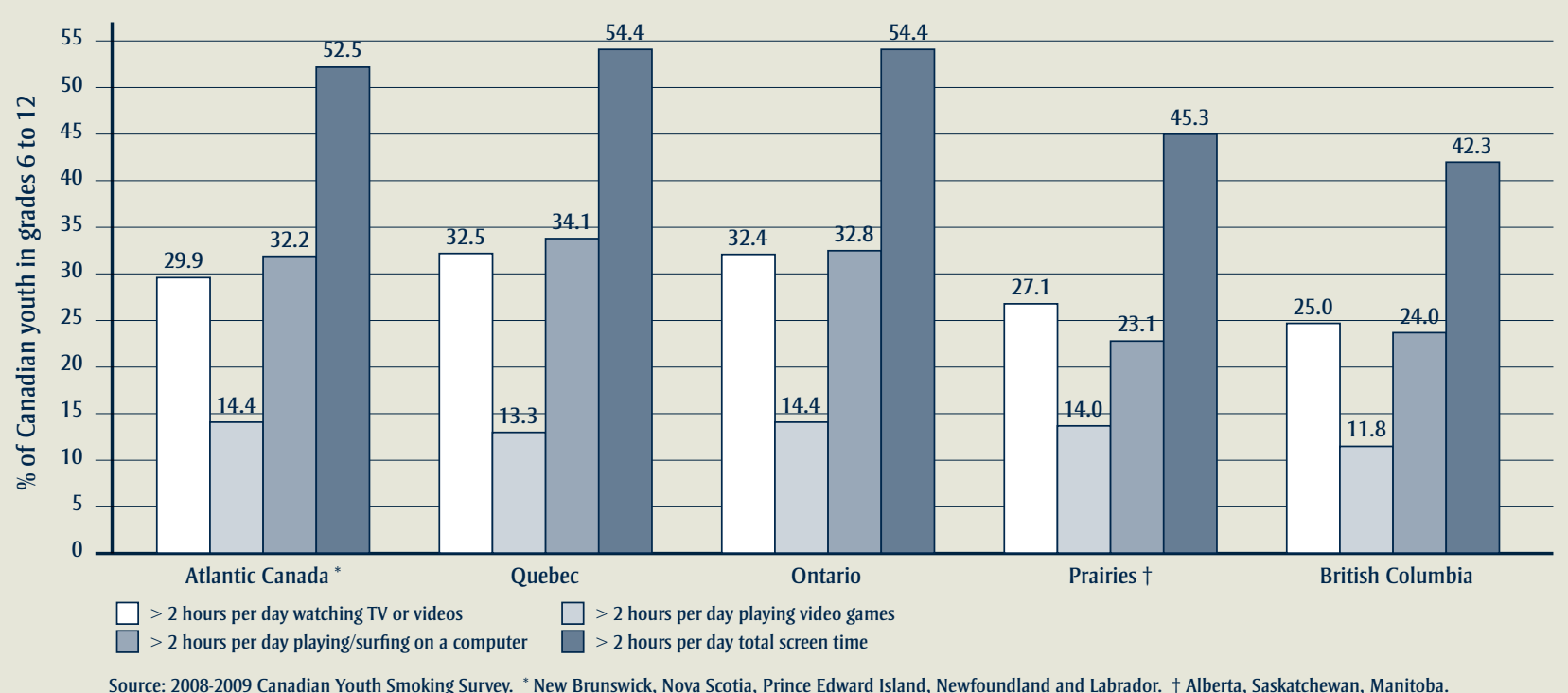

TABLE 2

Logistic regression analyses examining characteristics associated with screen-time behaviours among youth (grades 6 to 12) in the Youth Smoking Survey, 2008/2009, Canada

\begin{tabular}{|c|c|c|c|c|}
\hline \multirow[t]{2}{*}{ Characteristic } & \multicolumn{4}{|c|}{$\begin{array}{l}\text { Screen-time behaviour, adjusted } \mathrm{OR}^{\mathrm{a}}(95 \% \mathrm{CI}) \\
\qquad(\mathrm{n}=51 \mathrm{922})\end{array}$} \\
\hline & $\begin{array}{l}\text { Watching TV or videos }{ }^{b} \\
>2 h / d \text { vs. } \leq 2 h / d^{c}\end{array}$ & $\begin{array}{l}\text { Playing video games } \\
>2 h / d v s . \leq 2 h / d^{d}\end{array}$ & $\begin{array}{l}\text { Playing/surfing on a computer } \\
\quad>2 h / d \text { vs. } \leq 2 h / d^{e}\end{array}$ & $\begin{array}{l}\text { Total screen time } \\
>2 h / d \text { vs. } \leq 2 h / d^{f}\end{array}$ \\
\hline \multicolumn{5}{|l|}{ Sex } \\
\hline Female & 1.00 & 1.00 & 1.00 & 1.00 \\
\hline Male & $1.16(1.12-1.22)^{* * *}$ & $10.18(9.41-11.01)^{* * *}$ & $1.00(0.97-1.04)$ & $1.46(1.41-1.52)$ \\
\hline \multicolumn{5}{|l|}{ Grade } \\
\hline 6 & 1.00 & 1.00 & 1.00 & 1.00 \\
\hline 7 & $1.01(0.94-1.09)$ & $1.14(1.02-1.28)^{*}$ & $1.38(1.26-1.51)^{* * * *}$ & $1.16(1.08-1.25)^{* * *}$ \\
\hline 8 & $0.99(0.91-1.07)$ & $1.47(1.32-1.63)^{* * *}$ & $1.88(1.73-2.05)^{* * *}$ & $1.46(1.36-1.57)^{* * *}$ \\
\hline 9 & $0.83(0.77-0.90)^{* * *}$ & $1.20(1.07-1.34)^{* *}$ & $1.94(1.78-2.11)^{* * *}$ & $1.32(1.22-1.42)^{* * *}$ \\
\hline 10 & $0.82(0.76-0.89)^{* * *}$ & $0.99(0.89-1.11)$ & $1.86(1.71-2.03)^{* * *}$ & $1.18(1.09-1.27)^{* * *}$ \\
\hline 11 & $0.65(0.59-0.70)^{* * *}$ & $0.88(0.78-0.99)^{*}$ & $1.77(1.62-1.94)^{* * *}$ & $1.10(1.02-1.19)^{*}$ \\
\hline 12 & $0.71(0.65-0.77)^{* * *}$ & $0.59(0.52-0.68)^{* * *}$ & $1.80(1.64-1.98)^{* * *}$ & $1.09(1.01-1.18)^{*}$ \\
\hline \multicolumn{5}{|l|}{ Smoking status } \\
\hline Never smoker & 1.00 & 1.00 & 1.00 & 1.00 \\
\hline Current smoker & $1.15(1.06-1.24)^{* * * *}$ & $1.23(1.10-1.37)^{* * *}$ & $1.00(0.92-1.09)$ & $0.99(0.92-1.07)$ \\
\hline Former smoker & $1.27(1.01-1.58)^{*}$ & $1.26(0.92-1.72)$ & $0.61(0.47-0.78)^{* * *}$ & $0.89(0.72-1.09)$ \\
\hline \multicolumn{5}{|l|}{ Weekly spending money, \$ } \\
\hline 0 & 1.00 & 1.00 & 1.00 & 1.00 \\
\hline $1-20$ & $0.88(0.84-0.93)^{* * * *}$ & $0.86(0.80-0.93)^{* * *}$ & $1.06(1.00-1.12)^{*}$ & $0.95(0.90-0.99)^{*}$ \\
\hline $21-100$ & $0.89(0.84-0.93)^{* * *}$ & $0.81(0.74-0.88)^{* * *}$ & $1.14(1.07-1.22)^{* * *}$ & $0.97(0.91-1.02)$ \\
\hline$>100$ & $0.81(0.75-0.88)^{* * *}$ & $0.98(0.88-1.09)$ & $0.99(0.91-1.07)$ & $0.80(0.74-0.86)^{* * *}$ \\
\hline Self-esteem, each 1 unit increase & $0.91(0.90-0.92)^{* * *}$ & $0.88(0.87-0.90)^{* * *}$ & $0.85(0.84-0.86)^{* * *}$ & $0.85(0.84-0.86)^{* * *}$ \\
\hline \multicolumn{5}{|c|}{ Abbreviations: $\mathrm{Cl}$, confidence interval; d, day; h, hour; n, sample size; OR, odds ratio. } \\
\hline \multicolumn{5}{|c|}{ adds ratios controlling for region and adlusted for all other variables in the table. } \\
\hline \multicolumn{5}{|c|}{ b "Videos" refers to TV series or movies watched at home, on video tape, DVD or Blu-ray. } \\
\hline \multicolumn{5}{|c|}{$\begin{array}{l}\text { c } 1 \text { is the equivalent of }>2 \text { hours watching TV or videos per day }(n=12671), 0 \text { is the equivalent of } \leq 2 \text { hours watching TV or videos per day ( } n=30838 \text { ). } \\
\text { d } 1 \text { is the equivalent of }>2 \text { hours playing video games per day }(n=5818), 0 \text { is the equivalent of } \leq 2 \text { hours plaving video games per day ( } n=36724 \text { ). }\end{array}$} \\
\hline \multicolumn{5}{|c|}{ d 1 is the equivalent of $>2$ hours playing video games per day $(n=5818), 0$ is the equivalent of $\leq 2$ hours playing video games per day ( $n=36724)$. } \\
\hline \multicolumn{5}{|c|}{$\begin{array}{l}\text { e } 1 \text { is the equivalent of }>2 \text { hours playing/surfing on a computer per day }(n=12375), 0 \text { is the equivalent of } \leq 2 \text { hours playing/surfing on a computer per day ( } n=30298 \text { ). } \\
\text { f } 1 \text { is the equivalent of }>2 \text { hours total screen time per day }(n=22123) \text { is the equivalent of } \leq 2 \text { hours total screen time per day ( } n=22415) \text {. }\end{array}$} \\
\hline \multicolumn{5}{|c|}{$\begin{array}{l}\text { f } 1 \text { is the equivalent of }>2 \text { hours total screen time per day }(n=22123), 0 \text { is the equivalent of } \leq 2 \text { hours total screen time per day }(n=22415) \text {. } \\
{ }^{*} p<.05^{* *} p<.01{ }^{* * *} p<.001\end{array}$} \\
\hline
\end{tabular}


Boys were more likely than girls to report spending over 2 hours per day watching TV or videos $\left(\chi^{2}=23.3 ; d f=1 ; p<.001\right)$ and playing video games $\left(\chi^{2}=4164.0 ; d f=1\right.$; $p<.001$ ), whereas girls were more likely than boys to report spending over 2 hours per day playing or surfing on a computer $\left(\chi^{2}=66.2 ; d f=1 ; p<.001\right)$. Boys were also more likely than girls to spend over 2 hours per day in total screen time $\left(\chi^{2}=158.6\right.$; $d f=1 ; p<.001)$. Overall, students spent an average of $7.8( \pm 2.3)$ hours per day in these three sedentary activities (boys $8.3 \pm 2.5$ h/d; girls $7.3 \pm 2.1 \mathrm{~h} / \mathrm{d}$ ).

The prevalence of sedentary behaviours across regions varied substantially (see Figure 1). For instance, the prevalence of students reporting watching over 2 hours of TV or videos per day or playing or surfing on a computer was substantially lower in the Prairies and British Columbia than in the rest of Canada. Conversely, the prevalence of students reporting watching over 2 hours of total screen time per day was highest in Quebec and Ontario.

Watching TV or videos. Compared to never smokers, both current smokers and former smokers were more likely to report watching TV or videos (movies on video tape, DVD or Blu-ray) for over 2 hours per day (Table 2). Conversely, relative to students in grade 6 , students in grades $9,10,11$ or 12 were less likely to report watching TV or videos for over 2 hours per day. Compared to students with no weekly spending money, the odds of reporting watching over 2 hours of TV or videos per day decreased among students with weekly spending money. Students with lower self-esteem were more likely to report watching over 2 hours per day of TV or videos than students with higher self-esteem (Figure 2).

Playing video games. Compared to students in grade 6 , students in grades 7,8 and 9 were more likely to report playing video games for over 2 hours per day, and students in grades 11 and 12 were less likely to report playing video games for over 2 hours per day. Compared to students with no weekly spending money, the odds of reporting over 2 hours of video games per day decreased among students with $\$ 1$ to $\$ 100$ weekly spending money.
FIGURE 2

Model-based odds ratios for spending more than 2 hours per day watching TV, playing video games, or playing/surfing on a computer as a function of self-esteem among students in grades 6 to 12, Canada, 2008/2009

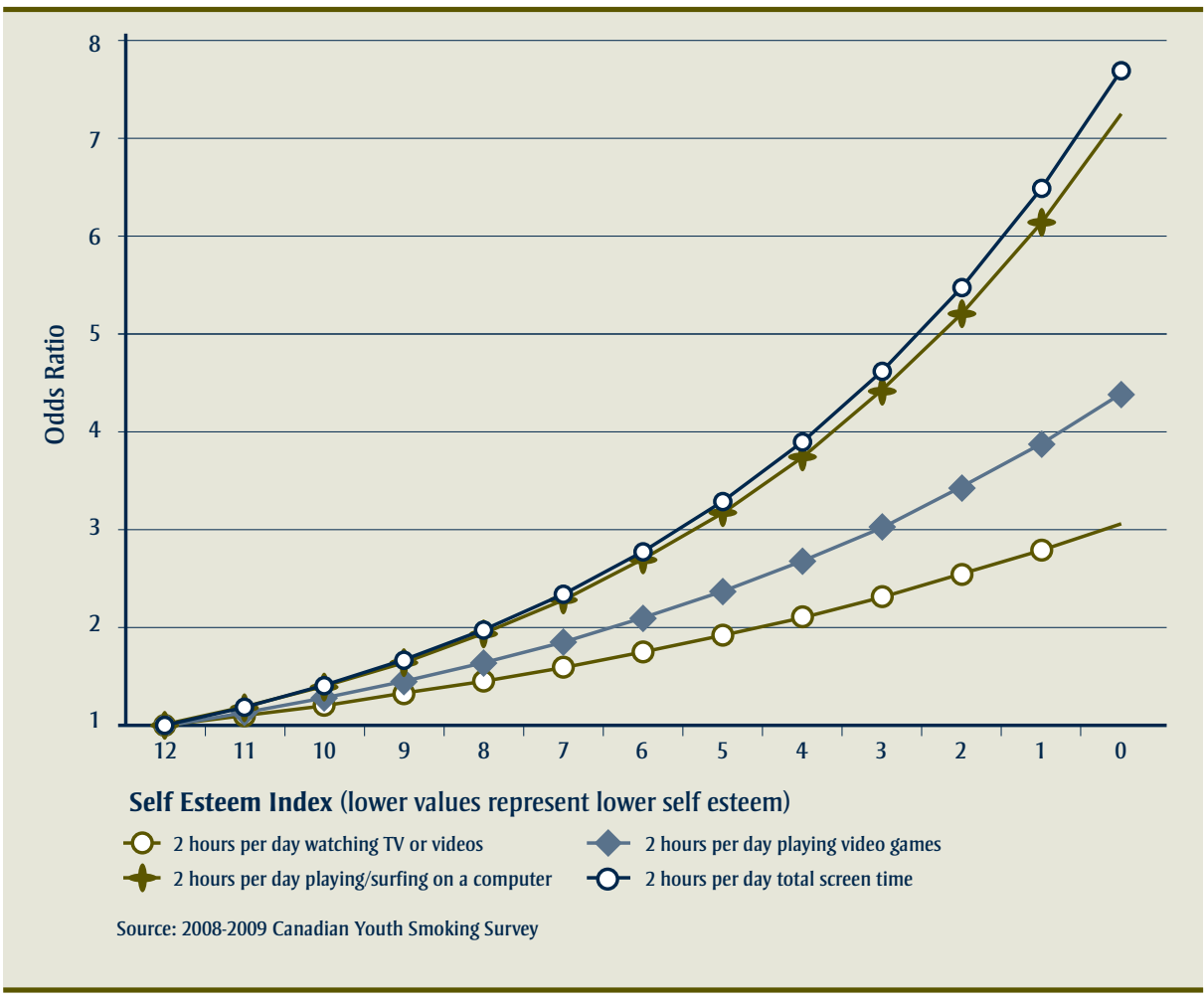

Current smokers were more likely than never smokers to report playing video games for over 2 hours per day. Students with lower self-esteem were more likely to report playing video games for over 2 hours per day than students with higher self-esteem (Figure 2).

Playing or surfing the Internet on a computer. Compared to students in grade 6 , students in higher grades were more likely to report playing or surfing on a computer for over 2 hours per day. Compared to students with no weekly spending money, the odds of reporting playing or surfing on a computer for over 2 hours per day increased among those with $\$ 1$ to $\$ 100$ weekly spen-ding money. Compared to never smokers, former smokers were less likely to report playing or surfing on a computer for over 2 hours per day. Students with lower self-esteem were more likely to report playing or surfing on a computer for over 2 hours per day than students with higher self-esteem (Figure 2).

Total screen time. Relative to students in grade 6 , students in higher grades were more likely to report over 2 hours of total screen time per day. Compared to students with no weekly spending money, the odds of reporting over 2 hours per day of total screen time decreased among students with over $\$ 100$ weekly spending money. Smoking status was not significantly associated with total screen time. Students with lower self-esteem were more likely to report over 2 hours per day of total screen time than students with higher self-esteem (Figure 2).

\section{Discussion}

Developing a better understanding of screentime behaviours and the factors associated with them can be used to inform the development of prevention programming among youth populations. This study showed that grade 6 to 12 students in our nationally representative sample are very involved in screen-time behaviours; these data also support the recommendation that intervention efforts to reduce screen time must begin prior to adolescence. ${ }^{17}$ Given that our 
sample demographics are consistent with other North American youth populations, ${ }^{18,19}$ these findings are fairly representative within that context.

Our study showed that the majority-over 1.4 million-of Canadian youth in grades 6 to 12 exceeded the recommended guidelines of less than 2 hours of screen time per day. ${ }^{4}$ Even when using a conservative estimate of average screen time, the youth in our sample exceeded existing guidelines by over 5 hours per day; the daily average time for each individual screen-based behaviour also exceeded recommendations for total screen time. A substantial number of youth exceeded the guideline recommendations based on their daily time spent in a single screen-time behaviour, consistent with previously published Canadian data from 2001/2002. ${ }^{6}$ This suggests that there is substantial room for decreasing screen time by at least 90 minutes per day as recommended by Canada's Physical Activity Guides for Children and Youth. ${ }^{20}$ However, considering that screen time is a behaviour distinct from a lack of physical activity ${ }^{15,21,22}$ and that many youth with high levels of screen time are also highly active, ${ }^{21}$ those behaviour-specific interventions that are designed to reduce screen time by promoting physical activity may be inadequate.

Consistent with earlier research, ${ }^{5,6,9-11}$ males were more likely to report more screen time than females. However, in our study this was not consistent across the three screenbased behaviours. Although boys were more likely to watch TV or videos and play video games for over 2 hours per day in the predictive models, the sex of the respondent was not significantly associated with time spent surfing or playing on a computer. Similarly, although earlier research suggested that older students are more likely to report more screen time than younger students, ${ }^{9}$ we found that students in higher grades were more likely to play/surf on a computer for over 2 hours per day but less likely to watch TV or videos or play video games for over 2 hours per day compared to grade 6 students. These findings suggest that further research is required to evaluate the impact of sex- or grade-specific interventions to reduce screen time among youth.
To the best of our knowledge, this is the first study to identify a significant association between self-esteem and screen-time behaviour, contradicting previous research that suggested self-esteem was not associated with sedentary behaviour. ${ }^{11}$ Since youth who are involved in sports and clubs after school have higher self-esteem than those who are not engaged in such activities, ${ }^{13}$ and rates of screen-time behaviours are highest after school, ${ }^{23}$ interventions should be designed to engage students in extracurricular activities that could reduce their screen time after school and improve their self-esteem. If effective, such interventions could be very important as low self-esteem and screen time have both been linked to numerous negative health outcomes among youth, such as smoking and other substance abuse. ${ }^{12,13}$

Earlier research suggested that youth with lower income parents are more likely to report more than 2 hours of screen time per day than youth with higher income parents. ${ }^{9}$ We found that the disposable income of students is associated with time spent in all three screen-based behaviours, but the direction of the association is not the same across all behaviours. This suggests that a tailored approach to reducing screen time may be required for youth populations based on their disposable income. Consistent with previous research, ${ }^{12}$ we also found that current smokers tended to spend more time watching TV and videos and playing video games. It would be useful to evaluate the impact of reducing sedentariness on the smoking behaviour of this sub-population of at-risk youth.

\section{Limitations}

This study had several limitations. Since no data on physical activity or obesity exist among the YSS measurement tools, we were unable to examine the association between screen time and these correlates. The measure used for sedentary behaviour in the 2008/2009 YSS do not allow us to calculate respondents' total sedentary time, or to determine the time spent in different sedentary behaviours on weekdays versus weekends. Although the 2008/2009 YSS collected a measure of time spent reading for fun, we did not include this in our research because education stakeholders consider reading for fun constructive due to its positive impact on educational performance rather than lacking a health benefit for youth. Further, causal relationships cannot be inferred from these cross-sectional data. Data were also based on self-reports so the validity of the responses may be questionable; however, honest reporting was encouraged by ensuring confidentiality during data collection.

\section{Conclusion}

With the high prevalence of Canadian youth exceeding recommended guidelines for screen time, we need to improve our understanding of the reasons for these sedentary behaviours and their correlates. This may be especially pertinent if the rise in obesity among youth populations is in fact influenced by an overall decrease in energy expenditure due to increased sedentary behaviour. Considering that most nationally representative surveillance data do not monitor different sedentary behaviours, ${ }^{24}$ the insight gained from this study provides a better understanding of the prevalence of different screen-time behaviours among Canadian youth as well as insight for tailoring future screen-time reduction interventions.

\section{Acknowledgement}

Dr. Scott Leatherdale is a Cancer Care Ontario Research Chair in Population Studies. The 2008/2009 Youth Smoking Survey is a product of a pan-Canadian capacity building project that includes Canadian researchers from all provinces and provides training opportunities for university students at all levels. Production of this paper was made possible through a financial contribution from Health Canada. The views expressed herein do not necessarily represent the views of Health Canada.

\section{References}

1. Hills AP, King NA, Armstrong TP. The contribution of physical activity and sedentary behaviours to the growth and development of children and adolescents: implications for overweight and obesity. Sports Med. 2007;37:533-45. 
2. Marshall SJ, Biddle SJ, Gorely T, Cameron $\mathrm{N}$, Murdey I. Relationships between media use, body fatness, and physical activity in children and youth: a meta-analysis. Int $\mathrm{J}$ Obes Relat Metab Disord. 2004;28:1238-46.

3. Crespo CJ, Smit E, Troiana RP, Bartlett SJ, Marcera CA, Andersen RE. Television watching, energy intake, and obesity in U.S. children: results from the third National Health and Nutrition Examination Survey, 1988-1994. Arch Pediatr Adolesc Med. 2001;155:360-5.

4. American Academy of Pediatrics. Committee on Public Education. Children, adolescents, and television. Pediatrics. 2001;107:423-6.

5. Carson V, Pickett W, Janssen I. Screen time and risk behaviors in 10- to 16-year-old Canadian youth. Prev Med. 2010;52:99-103. Doi:10.1016/j.ypmed.2010.07.005.

6. Mark AE, Boyce WF, Janssen I. Television viewing, computer use and total screen time in Canadian youth. Paediatr Child Health. 2006;11:595-9.

7. Steffen LM, Dai S, Fulton JE, Labarthe DR. Overweight in children and adolescents associated with TV viewing and parental weight: Project HeartBeat! Am J Prev Med. 2009;37:s50-5.

8. Koezuka N, Koo M, Allison KR, Adlaf EM, Dwyer JJ, Faulkner G, et al. The relationship between sedentary activities and physical inactivity among adolescents: results from the Canadian Community Health Survey. J Adolesc Health. 2006;39:515-22.

9. Carlson SA, Fulton JE, Lee SM, Foley JT, Heitzler C, Huhman M. Influence of limitsetting and participation in physical activity on youth screen time. Pediatrics. 2010;126: e89-e96.

10. Barnett TA, O’Loughlin J, Sabiston CM, Karp I, Bélanger M, Van Hulst A, et al. Teens and screens: the influence of screen time on adiposity in adolescents. Am J Epidemiol. 2010;172:255-62
11. Van der Horst K, Paw MJ, Twisk JW, van Mechelen W. A brief review on correlates of physical activity and sedentariness in youth. Med Sci Sports Exerc. 2007;39:1241-50.

12. Hancox RJ, Milne BJ, Poulton R. Association between child and adolescent television viewing and adult health: a longitudinal birth cohort study. Lancet. 2004;364:257-62.

13. Kort-Butler LA, Hagewen KJ. School-based extracurricular activity involvement and adolescent self-esteem: a growth curve analysis. J Youth Adolesc. 2010. Doi 10.1007/ s10964-010-9551-4.

14. Health Canada. 2008-09 Youth Smoking Survey. Ottawa (ON): Minister of Supply and Services Canada; 2010 [cited 2010 Jul 25]. Available at: http://www.hc-sc.gc.ca /hc-ps/tobac-tabac/research-recherche/stat /_survey-sondage_2008-2009/result-eng.php

15. Leatherdale ST, Wong SL. Modifiable characteristics associated with sedentary behaviours among youth. Int $\mathrm{J}$ Pediatr Obes. 2008;3:93-101.

16. SAS Institute Inc. The SAS System for Windows. Cary (NC): SAS Institute Inc; 2001.

17. Gordon-Larsen P, Nelson MC, Popkin BM. Longitudinal physical activity and sedentary behavior trends: adolescence to adulthood. Am J Prev Med. 2004;27:277-83.

18. Ogden CL, Flegal KM, Carroll MD, Johnson CL. Prevalence and trends in overweight among US children and adolescents, 19992000. JAMA. 2002;288:1728-32.

19. Shields M. Overweight and obesity among children and youth. Health Rep. 2006;17: 27-42.

20. Public Health Agency of Canada. Canada's physical activity guides for children and youth [Internet]. Ottawa (ON): Public Health of Canada; [cited 2007 Jul 10]. http://www .phac-aspc.gc.ca/pau-uap/paguide/child_ youth/index.html
21. Wong SL, Leatherdale ST. Association between sedentary behavior, physical activity, and obesity: inactivity among active kids. Prev Chronic Dis [Internet]. 2009 [cited 2010 Jul 25];6(1). Available from: http://www.cdc.gov/pcd/issues/2009/jan /07_0242.htm

22. Biddle SJ, Gorely T, Stensel DJ. Healthenhancing physical activity and sedentary behaviour in children and adolescents. J Sports Sci. 2004;22:679-701.

23. Biddle SJ, Marshall SJ, Gorely T, Cameron $\mathrm{N}$. Temporal and environmental patterns of sedentary and active behaviors during adolescents' leisure time. Int J Behav Med. 2009;16:278-86.

24. Spanier PA, Marshall SJ, Faulkner GE. Tackling the obesity epidemic: a call for sedentary behaviour research. Can J Pub Health. 2006;97:255-7. 